SCIDic

\section{Analysis of Interleukin-10 (-1082) G/A Gene Polymorphism in Chronic Periodontitis among Saudi Population}

ISSN: $2377-8075$

Research Article

Bader S. Alghamdi ${ }^{1}$, Abdullaziz M. Alzhrani ${ }^{1}$, Faisal Y. Alfeifi ${ }^{1}$, Fathy M. Elfasakhany ${ }^{2,3, *}$, Alaa M. Moustafa ${ }^{2,4}$, Ehab Azab ${ }^{2}$, Mashael S. Alqahtani ${ }^{2}$

${ }^{1}$ Dental intern program, Faculty of Dentistry, Umm Al Qura University, Makkah, Saudi Arabia.

${ }^{2}$ Department of Basic and Clinical Oral Sciences, Faculty of Dentistry, Umm Al Qura University, Makkah, Saudi Arabia.

${ }^{3}$ Department of Medical Biochemistry, Faculty of Medicine, Tanta University, Tanta, Egypt.

${ }^{4}$ Department of Oral Medicine and periodontology, Faculty of Dentistry, Al-Azhar University, Assiut, Egypt.

\title{
Abstract
}

Background: Periodontitis is a major oral health problem and it accounts one of the causes for tooth loss. Hereditary factors have a critical role in the development of periodontitis.

Objectives: This study aimed to analyze the influence of the interleukin-10 (-1082) G/A (rs1800896) polymorphism and the risk of periodontal disease among Saudi population in Makkah environ.

Materials and Methods: Peripheral blood leucocytes were used for extraction of DNA which was used for genotyping of interleukin-10 (IL-10) gene in 83 healthy controls and 60 unrelated Saudi patients with generalized moderate to severe periodontitis using polymerase chain reaction based restriction fragment length polymorphism (RFLP).

Results: The distribution of AA genotype was higher in periodontitis group relative to the control group while the GG genotype was higher in the control group compared with the patients with periodontitis ( $\mathrm{OR}=3.43,95 \% \mathrm{CI}: 1.44-8.17, \mathrm{P}=$ 0.006). The AG genotype did not show significant difference between controls and periodontitis group $(\mathrm{OR}=1.951,95 \%$ CI: $0.85-4.47, \mathrm{P}=0.14$ ). The distribution of A allele was higher in periodontitis relative to the controls while the $\mathrm{G}$ allele was higher in control group compared with the periodontitis group $(\mathrm{OR}=2.52,95 \% \mathrm{CI}: 1.20-5.27, \mathrm{P}=0.013)$.

Conclusion: These results suggested that the AA genotypes and A allele of IL-10 (-1082) G/A polymorphism may be associated with periodontitis among Saudi population while the GG genotype and the G allele may be associated with decreased risk of periodontitis.

Keywords: Gene Polymorphism; Periodontitis; IL-10; PCR; Restriction Enzyme.

\section{Introduction}

Periodontitis is a chronic infectious condition of the teeth supporting tissues and is commonly counted as a gradually progressing and multifactorial sickness. Nonetheless, in the existence of environmental or systemic factors which could alter the host reaction to plaque accumulation, like diabetes, smoking, or stress, the illness progression may develop into extra aggressive form [1]. The predominant scientific and etiologic aspects of the disorder are microbial plaque development, periodontal inflammation, loss of attachment and alveolar bone [2]. Characteristic clinical findings in patients with untreated periodontitis may encompass supragingival and subgingival plaque accumulation which is com- monly accompanied by calculus formation, gingival inflammation, pocket formation, lack of periodontal attachment, loss of alveolar bone and occasional suppuration [1]. The occurrence and severity of periodontitis increase with the age and typically affecting each gender equally. Furthermore, periodontal destruction is frequently visible among family individuals and across different generations within a family, suggesting a genetic foundation for the susceptibility to periodontal disease [3, 4]. Cytokines and inflammatory mediators play a key role in pathogenesis of periodontal diseases. Several proinflammatory cytokines such as TNF- $\alpha$, interlukin-1 $\beta$ (IL-1 $\beta$ ), IL-6, IL-8 and IL-17 upregulate the inflammatory process within periodontal tissues [2, 5]. Meanwhile, there are some anti-inflammatory cytokines that down regulate the inflammation in periodontal tissues, such as IL-4,

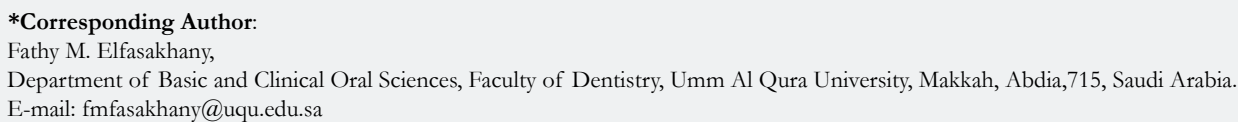

Citation: Bader S. Alghamdi, Abdullaziz M. Alzhrani, Faisal Y. Alfeifi, Fathy M. Elfasakhany, Alaa M. Moustafa, Ehab Azab, et al.,. Analysis of Interleukin-10 (-1082) G/A Gene Polymorphism in Chronic Periodontitis among Saudi Population. Int J Dentistry Oral Sci. 2020;7(8):794-798. doi: http://dx.doi.org/10.19070/2377-8075-20000156

Copyright: Fathy M. Elfasakhany ${ }^{\circ} 2020$. This is an open-access article distributed under the terms of the Creative Commons Attribution License, which permits unrestricted use, distribution and reproduction in any medium, provided the original author and source are credited. 
IL-10 and Transforming growth factor- $\beta$ (TGF- $\beta$ ) [5]. Within the last 2 decades there were several studies describing the gene polymorphisms in relation to periodontitis as genetic risk factors for progression of inflammatory periodontal condition. Several gene polymorphisms were tested such as TNF- $\alpha$, IL- $1 \beta$, IL-6, IL-8, IL-4, IL-10, TGF- $\beta$ and matrix metalloproteinases-8 (MMP-8) $[1,2,6]$. IL-10 is a strong anti-inflammatory cytokine which has a critical function in stopping inflammatory and autoimmune reactions. Deficiency of IL-10 expression can promote inflammatory response to microbial contamination. IL-10 was defined in different cells such as T helper cells, dendritic cells, B cells, monocytes, Macrophages, NK cells, mast cells, granulocytes like neutrophils and eosinophils or even is produced with non-immune types of cells such as epithelial cells and keratinocytes in reaction to bacterial infection or tissue damage [7]. It has been suggested that the IL-10 performs an essential function in periodontal illnesses and IL-10 deficiency was associated with alveolar bone resorption and reducing bone formation. Several studies found out that the IL-10 promoter region polymorphism may be involved with the development of periodontal illnesses. A group of polymorphisms of the IL-10 gene within the promoter region, including -1082 (-1087)A/G, -819 (-824)C/T and -592(-597)C/A had been associated with periodontitis, albeit at varying frequencies in subjects from diverse ethnic background [8]. The IL-10 (-1082) G/A gene polymorphism in chronic periodontitis was studied in Peruvian populace and the investigators reported that AA genotype of IL10 (-1082) polymorphism is as $\neg$ sociated with CP [9]. Moreover, other investigators showed that there is statistical association between IL-10 -819 C/T and IL-10 -592 C/A polymorphisms and chronic periodontitis in Caucasian population [10]. Hence the research on IL-10 gene polymorphism in CP patients suggests contrary outcomes among different ethnic populations, we investigated the association between the IL-10 (-1082) G/A (rs1800896) polymorphism in Saudis with moderate to severe periodontitis.

\section{Materials and Methods}

\section{Study design and Participants}

A total of one hundred forty three subjects (sixty unrelated patients with moderate to severe periodontitis and eighty three healthy control subjects) have been selected from the dental clinics within the faculty of dentistry, Umm AL Qura University, Makkah, Saudi Arabia. All subjects who participated in the study were Saudi individuals. The inclusion criteria to select controls were the absence of both systemic and periodontal diseases. Both groups had been matched concerning the age (30-50 years) and gender and presented with at least twenty teeth. The exclusion criteria include pregnancy, lactation, history of systemic disorders, immunodeficiency diseases, chemotherapy, persons with previous orthodontic therapy and smokers. All subjects were asked to fill and sign informed consent before participation in the study. The sample size was calculated on the basis of a previous study regarding the association of IL-10 (-1082) G/A polymorphism with periodontal disease [9]. It was increased by $30 \%$ to maintain the estimates at an optimal level of precision (5\%) against the potential effect of sample size reduction due to exclusions and dropouts.

\section{Periodontal examination}

All individuals were examined and the periodontal condition was evaluated primarily based on the subsequent parameters: bleeding on probing (BOP) [11], plaque index (PI) [12], probing depth (PD) and clinical attachment loss (CAL) [13] by three trained and calibrated investigators. Subjects presented with bleeding on probing, $\mathrm{PD} \geq 5 \mathrm{~mm}, \mathrm{CAL} \geq 3 \mathrm{~mm}$ and evidence of radiographic bone loss $\geq 20 \%$ were included in the chronic periodontitis group. The diagnostic criteria of moderate to severe chronic periodontitis followed the task force updated report of the American Academy of periodontology [14].

\section{Blood sample collection}

Venous blood samples were collected from all subjects in K3EDTA (tri-potassium ethylene diamine tetraacetic acid) coated tubes. The buffy coat white cells were used for preparation of genomic DNA. All specimens were kept at $-20^{\circ} \mathrm{C}$ until the time of use.

\section{Genomic DNA extraction}

Peripheral blood leukocytes were used for extraction of genomic DNA using DNA preparation kit (QIAamp DNA Blood Mini Kits, Qiagen, Hilden, Germany) consistent with the commands of the maker. Aliquots of genomic DNA were utilized for PCR amplification.

\section{IL-10 (-1082 ) G/A genotyping}

IL-10 polymorphism at the position -1082 bp, was determined utilizing the PCR-restriction fragment length polymorphism in line with the approach described before with some modifications [15]. The PCR was done in $20 \mu \mathrm{l}$ total reaction volume utilizing the primers: 5'-5'CCAAGAC AAC ACTACTAAGGCTCCT'TT3' -3' as forward primer and 5'- 5'GCTTCTT ATATGCTA GTCAGGTA - $3^{\prime}$ as a reverse primer. The PCR program includes beginning step for $3 \mathrm{~min}$ at $94^{\circ} \mathrm{C}$; then forty cycles at $94^{\circ} \mathrm{C}$ for 30 sec, $56^{\circ} \mathrm{C}$ for $35 \mathrm{sec}$, and $72^{\circ} \mathrm{C}$ for $30 \mathrm{sec}$; and a final step at $72^{\circ} \mathrm{C}$ for 5 minutes and the expected size of the PCR product was 377 bp. The product of PCR was cut with XagI restriction enzyme (Thermo Fisher Scientific) and separated on agarose gel with a concentration of $2.0 \%$ and then analyzed under ultraviolet light. Genotypes were identified according to the following pattern: A/A genotype gave two bands of $280 \mathrm{bp}$ and $97 \mathrm{bp}$ and $\mathrm{G} / \mathrm{G}$ genotype gave three bands of $253 \mathrm{bp}, 97 \mathrm{bp}$ and $27 \mathrm{bp}$.

\section{Statistical analysis}

Data were analyzed utilizing SPSS version 20 for Windows (SPSS Inc, Chicago. IL, USA). Analysis of the continuous variable in periodontitis cases and controls was performed using Student's t-test, whereas $\chi^{2}$ analysis was utilized to analyze the categorical data. The difference between groups was considered statistically significant if $P<0.05$. Odds ratio (OR) was calculated with $95 \%$ confidence interval (CI).

\section{Results}

\section{Clinical measurements}

The difference in clinical measurements (BOP, CAL, PI and PD) between subjects with or without periodontitis is presented in Table 1. There was significant difference between control and periodontitis groups for the mean values of BOP, CAL, PI and PD 
$(\mathrm{P}<0.001)$. This gave an evidence that the matching between the two groups was adequate.

\section{IL-10 (-1082) G/A polymorphism}

The frequencies of the genotypes and alleles of IL-10 (-1082) $\mathrm{G} / \mathrm{A}$ polymorphism at the promoter region in both periodontitis and control groups are presented in Table 2. The genotype distribution of IL-10 (-1082) polymorphism was in Hardy-Weinberg equilibrium in both the controls and the periodontitis subjects. In the control group, the genotypes AA, AG and GG were 21.68 $\%, 34.93 \%$ and $43.37 \%$ respectively and were $40 \%, 36.66 \%$ and $23.33 \%$ respectively in the periodontitis group. The AA genotype was higher in the periodontitis subjects relative to controls while the GG genotype was higher in the control group relative to patient group (OR $=3.43,95 \% \mathrm{CI}: 1.44-8.17, \mathrm{P}=0.006)$. The AG genotype did not show significant difference between controls and the periodontitis subjects (OR $=1.951,95 \% \mathrm{CI}: 0.85-4.47, \mathrm{P}$ - 0.14). The percentage of A allele was $39.15 \%$ and $58.33 \%$ while G allele was $60.84 \%$ and $41.66 \%$ in control and the periodontitis groups respectively. The A allele was higher in the periodontitis group than the control subjects while the $G$ allele was higher in the controls relative the periodontitis group $(\mathrm{OR}=2.52,95 \% \mathrm{CI}$ : 1.20-5.27, $\mathrm{P}=0.013)$. This means that AA genotype and subjects carrying the A allele may have higher risk for periodontitis than subjects with GG genotypes who have low risk of periodontitis

Table 1. Demographic and clinical data of study population.

\begin{tabular}{|c|c|c|c|}
\hline Characteristics & Control group (83) & Periodontitis group (60) & P value \\
\hline Age (years) & $41.26 \pm 6.1$ & $42.22 \pm 5.96$ & 0.294 \\
\hline Gender (M/F) & $51 / 32$ & $36 / 24$ & 0.861 \\
\hline BOP $(\%)$ & $10.13 \pm 4.01$ & $46.77 \pm 7.64$ & $<0.001$ \\
\hline PD $(\mathrm{mm})$ & $1.19 \pm 0.26$ & $5.28 \pm 0.86$ & $<0.001$ \\
\hline CAL $(\mathrm{mm})$ & $1.34 \pm 0.57$ & $4.5 \pm 1.08$ & $<0.001$ \\
\hline PI $(\%)$ & $5.64 \pm 2.97$ & $47.95 \pm 8.52$ & $<0.001$ \\
\hline
\end{tabular}

Data are shown as mean \pm SD. P-value \pm 0.05 was considered as significant.

Table 2. Genotype and allele frequencies of the IL-10 (-1082)G/A polymorphism in the study groups.

\begin{tabular}{|c|c|c|c|c|c|c|c|c|}
\hline \multirow{2}{*}{$\begin{array}{l}\text { IL-10 (-1082) } \\
\text { polymorphism }\end{array}$} & \multicolumn{2}{|c|}{$\begin{array}{c}\text { Control } \\
(n=83)\end{array}$} & \multicolumn{2}{|c|}{$\begin{array}{l}\text { Periodonti- } \\
\text { tis }(n=60)\end{array}$} & \multirow[t]{2}{*}{${ }^{\mathrm{a}} \chi^{2}$} & \multirow[t]{2}{*}{$* P$ value } & \multirow[t]{2}{*}{ Odds ratio } & \multirow[t]{2}{*}{$95 \% \mathrm{CI}$} \\
\hline & $\%$ & No & $\%$ & No & & & & \\
\hline \multicolumn{9}{|l|}{ Genotypes: } \\
\hline GG & 43.37 & 36 & 23.33 & 14 & & & 1 & \\
\hline AG & 34.93 & 29 & 36.66 & 22 & 2.52 & 0.14 & 1.951 & $0.85-4.47$ \\
\hline$\overline{\mathrm{AA}}$ & 21.68 & 18 & 40 & 24 & 7.99 & 0.006 & 3.43 & $1.44-8.17$ \\
\hline \multicolumn{9}{|l|}{ Alleles: } \\
\hline $\mathrm{G}$ & 60.84 & 101 & 41.66 & 50 & & & 1 & \\
\hline A & 39.15 & 65 & 58.33 & 70 & 6.15 & 0.013 & 2.52 & $1.20-5.27$ \\
\hline
\end{tabular}

${ }^{a}$ Chi-square analysis of genotypes between patients with periodontitis and healthy controls. $* \mathrm{P}$-value $<0.05$ was considered as significant.

Table 3. Characteristics of different genotypes of IL-10 (-1082) gene polymorphism in controls and subjects with periodontitis (GG vs AG+AA).

\begin{tabular}{|c|c|c|c|c|}
\hline \multirow{4}{*}{ Controls } & \multicolumn{4}{|c|}{ IL-10 (-1082) polymorphism (GG vs AG plus AA) } \\
\cline { 2 - 5 } & Characteristics & GG & AG+AA & P value \\
\hline \multirow{4}{*}{} & No. & 36 & 47 & \\
\cline { 2 - 5 } & BOP $(\%)$ & $9.54 \pm 3.76$ & $10.58 \pm 4.17$ & 0.243 \\
\cline { 2 - 5 } & PD (mm) & $1.14 \pm 0.26$ & $1.21 \pm 0.27$ & 0.251 \\
\cline { 2 - 5 } & CAL (mm) & $1.25 \pm 0.59$ & $1.41 \pm 0.55$ & 0.187 \\
\cline { 2 - 5 } & PI (\%) & $5.69 \pm 2.89$ & $5.59 \pm 3.05$ & 0.882 \\
\hline \multirow{5}{*}{ Periodontitis } & No. & 14 & 46 & \\
\cline { 2 - 5 } & BOP $(\%)$ & $44.57 \pm 7.8$ & $47.73 \pm 7.4$ & 0.074 \\
\cline { 2 - 5 } & PD (mm) & $5.37 \pm 0.97$ & $5.24 \pm 0.82$ & 0.635 \\
\cline { 2 - 5 } & CAL (mm) & $4.56 \pm 0.96$ & $4.45 \pm 1.11$ & 0.363 \\
\cline { 2 - 5 } & PI (\%) & $48.5 \pm 6.91$ & $47.78 \pm 9.02$ & 0.786 \\
\hline
\end{tabular}

Analysis of GG vs AG+AA genotypes in both periodontitis and healthy controls using Student's t-test. Data are shown as mean \pm SD. P-value $<0.05$ was considered as significant. 
(Table 2).

\section{Clinical data in the GG genotype compared with the AG plus AA genotypes}

Table 3 shows comparison of the clinical data [(BOP (\%), PD $(\mathrm{mm})$, CAL (mm) and PI (\%)] of the GG genotype relative to the AG plus AA genotypes of both control and periodontitis subjects. There was no significant difference between GG genotype and $A G$ plus $A A$ genotypes in both controls and the periodontitis subjects regarding BOP (\%), PD (mm), CAL (mm) and PI (\%).

\section{Discussion}

Periodontitis is a chronic inflammatory disease of the supporting tissues of the tooth that result in destruction of the periodontal ligament and alveolar bone due to interaction between pathogenic bacteria and host immune response [1]. The balance between proinflammatory and anti-inflammatory events is crucial for determining disease progression, and it is now clear that individual cytokines do not act in isolation but rather as part of complex networks of mediators that have different functional activities [16]. A number of anti-inflammatory cytokines are reported such as IL-10, TGF- $\beta$, IL-1Ra, IL-1F5, and possibly IL-1F10 [1]. IL 10 has a role in viral infections and the resulting tissue damage through stimulating the release of immune factors, phagocytosis control and presentation of the antigen. Also, IL 10 has a role in improving of both innate and adaptive immunity [17]. The encoding gene of IL 10 is present on chromosome 1q31 32. Polymorphisms in the IL 10 promoter region may affect the IL 10 expression and this may be followed by changes in the inflammatory processes [18]. However, the results of the association between IL 10 polymorphisms and CP among different ethnic populations showed conflicting results [19-21]. We have analyzed the association between IL-10(-1082) G/A (rs1800896) polymorphism and the risk of chronic periodontitis among Saudi population in Makkah environ. The AA genotype and A allele were found to be higher in the periodontitis group relative to the controls $(\mathrm{P}=0.006$ and 0.013 respectively) while the GG genotype and $G$ allele were found to be higher in control subjects relative to the periodontitis group. Therefore, we suggested that AA genotype and A allele may be associated with periodontitis among Saudis while GG genotype and $G$ allele do not confer higher significant risk for periodontitis. Similar results were obtained in a number of ethnic populations (Peruvian population [9]; Indian populations [22]; Jordanian population [23]; Italian San Patrignano Community in Northern Italy [24] and Iranian population [25]. These findings were in agreement with our study. On the other hand, other investigators did not find an association between IL-10 (-1082) G/A polymorphism and the risk of chronic periodontitis as Caucasian population [19] and Brazilian population [15, 26, 27]. However, several investigators obtained significant association between GG genotype of -1082 (G/A) IL-10 polymorphism while AA genotype may not have a risk for chronic periodontitis as in Iranian population from Southeast of Iran [28]; Macedonian population [29]; Swedish population [30] and Chinese population [31]. These results are contrary to our results. These opposite results might be explained by the difference in genetic background and exposure to environmental factors.

Based on above, the results of studies on the association and sus- ceptibility of IL-10 (-1082) G/A gene polymorphism of and the risk of periodontitis differ from one population to another.

To the best of our knowledge, this is the first research work in Saudi Arabia studying the association between IL-10 (-1082) $\mathrm{G} / \mathrm{A}$ polymorphism and the risk of chronic periodontitis.

Numerous studies have revealed that IL-10 (-1082) G/A polymorphisms are related to other chronic diseases other than chronic periodontitis such as hepatitis B virus infection [18]; Crohn's disease [32]; sepsis susceptibility [33] and myocardial ischemia [34]. The limitation in this study is the small number of studied subjects. Further studies will be needed in a large chronic periodontitis cohort with clinical data and serological analysis to understand the role of IL-10 and IL-10 (-1082) G/A polymorphism in the pathogenesis of chronic periodontitis.

\section{Conclusion}

The obtained findings suggested that the IL-10 (-1082) AA genotype and A allele were associated with periodontitis risk in Saudi population affected by moderate to severe periodontitis compared with the healthy subjects while GG genotype does not carry high significant risk for periodontitis. Future studies on larger sample size of patients with different forms of periodontitis are required to clarify the role of the genetic polymorphism of IL-10 in the pathogenesis of periodontitis.

\section{Ethical Statement}

This study was approved by the Ethics Review Board of the Faculty of Dentistry, Umm Al Qura University, Makkah, Saudi Arabia. These guidelines of the IRB follow the Saudi and International ethics and patient protection guidelines that follows the Declaration of Helsinki in 1995 (as revised in Fortaleza, Brazil, October 2013).

\section{Acknowledgment}

The authors thank Dr. Abdulrahman Yousuf for his technical support in the research laboratory in Faculty of Dentistry, Um AlQura University, Saudi Arabia. Also, authors thank Dr. AbdeAziz Yasin for his help in the statistics section.

\section{References}

[1]. Newman MG, Takei H, Klokkevold PR, Carranza FA. Newman and Carranza's clinical periodontology. Philadelphia; Elsevier. 2019; 342-351.

[2]. Heidari Z, Moudi B, Mahmoudzadeh-Sagheb H. Immunomodulatory factors gene polymorphisms in chronic periodontitis: an overview. BMC Oral Health. 2019; 19:29. PMID: 30755190.

[3]. Könönen E, Gursoy M, Gursoy UK. Periodontitis: A Multifaceted Disease of Tooth-Supporting Tissues. J Clin Med. 2019; 8(8): 1135. PMID: 31370168.

[4]. Toy VE, Uslu MO. Do genetic polymorphisms affect susceptibility to periodontal disease? A literature review. Niger J Clin Pract. 2019; 4:445-453. PMID: 30975946.

[5]. Yucel-Lindberg T, Båge T. Inflammatory mediators in the pathogenesis of periodontitis. Expert Rev Mol Med. 2013; 15:e7. PMID: 23915822.

[6]. Laine ML, Crielaard W, Loos BG. Genetic susceptibility to periodontitis. Periodontol 2000. 2012; 58:37-68. PMID: 22133366.

[7]. Iyer SS, Cheng G. Role of interleukin 10 transcriptional regulation in inflammation and autoimmune disease. Crit Rev Immunol. 2012; 32:23-63. PMID: 22428854. 
[8]. Zhang Q, Chen B, Yan F, Guo J, Zhu X, Ma S, et al. Interleukin-10 inhibits bone resorption: a potential therapeutic strategy in periodontitis and other bone loss diseases. Biomed Res Int. 2014; 2014. PMID: 24696846.

[9]. Chambrone L, Ascarza A, Guerrero ME, Pannuti C, de la Rosa M, SalinasPrieto E, et al. Association of -1082 interleukin-10 gene polymorphism in Peruvian adults with chronic periodontitis. Med Oral Patol Oral Cir Bucal. 2014; 19: e569.

[10]. Albuquerque CM, Cortinhas AJ, Morinha FJ, Leitão JC, Viegas CA, Bastos EM. Association of the IL-10 polymorphisms and periodontitis: a metaanalysis. Mol Biol Rep. 2012; 39:9319-29. PMID: 22763734

[11]. Ainamo J, Bay I. Problems and proposals for recording gingivitis and plaque. Int Dent J. 1975; 25:229-35. PMID: 1058834.

[12]. O'Leary TJ, Drake RB, Naylor JE. The plaque control record. J Periodontol. 1972; 43:38. PMID: 4500182.

[13]. Ramfjord SP, Emslie RD, Greene JC, Held AJ, Waerhaug J. Epidemiological studies of periodontal diseases. Am J Public Health Nations Health 1968; 58: 1713-22. PMID: 5692059.

[14]. Periodontitis O. American Academy of Periodontology Task Force Report on the Update to the 1999 Classification of Periodontal Diseases and Conditions. J Periodontol. 2015; 86: 835-8.

[15]. Moreira P, Costa J, Gomez R, Gollob K, Dutra W. TNFA and IL10 Gene Polymorphisms are not Associated with Periodontitis in Brazilians. The Open Dentistry Journal. 2009; 3:184-190. PMID: 19771178.

[16]. Cicchese JM, Evans S, Hult C, Joslyn LR, Wessler T, Millar JA, et al. Dynamic balance of pro- and anti inflammatory signals controls disease and limits pathology. Immunol Rev. 2018; 285:147-167. PMID: 30129209.

[17]. Ouyang W, Rutz S, Crellin NK, Valdez PA, Hymowitz SG. Regulation and functions of the IL-10 family of cytokines in inflammation and disease. Annu Rev Immunol. 2011; 29:71-109. PMID: 21166540.

[18]. Moudi B, Heidari Z, Mahmoudzadeh-Sagheb H, Hashemi M, Metanat M, Khosravi $S$, et al. Association between IL-10 gene promoter polymorphisms (-592 A/C, $-819 \mathrm{~T} / \mathrm{C},-1082 \mathrm{~A} / \mathrm{G})$ and susceptibility to HBV infection in an Iranian population. Hepat Mon. 2016; 16: e32427. PMID: 27148384.

[19]. Zhong Q, Ding C, Wang M, Sun Y, Xu Y. Interleukin-10 gene polymorphisms and chronic/aggressive periodontitis susceptibility: a meta-analysis based on 14 case-control studies. Cytokine. 2012; 60:47-54. PMID: 22698805.

[20]. Yang SL, Huang SJ. Interleukin-10 polymorphisms (rs1800871, rs1800872 and rs1800896) and periodontitis risk: A meta-analysis. Arch Oral Biol. 2019; 97:59-66. PMID: 30343215.

[21]. Wong HC, Ooi Y, Pulikkotil SJ, Naing C. The role of three interleukin 10 gene polymorphisms $(-1082 \mathrm{~A}>\mathrm{G},-819 \mathrm{C}>\mathrm{T},-592 \mathrm{~A}>\mathrm{C})$ in the risk of chronic and aggressive periodontitis: a meta-analysis and trial sequential analysis. BMC Oral Health. 2018; 18:171. PMID: 30348144.

[22]. Crena J, Subramanian S, Victor DJ, Gnana PPS, Ramanathan A. Single nucleotide polymorphism at -1087 locus of interleukin-10 gene promoter is associated with severe chronic periodontitis in nonsmoking patients. Eur J Dent. 2015; 9:387-393.

[23]. Jaradat SM, Ababneh KT, Jaradat SA, Abbadi MS, Taha AH, Karasneh JA, et al. Association of interleukin-10 gene promoter polymorphisms with chronic and aggressive periodontitis. Oral Dis. 2012; 18:271-9. PMID: 22077544.

[24]. Ianni M, Bruzzesi G, Pugliese D, Porcellini E, Carbone I, Schiavone A, et al Variations in inflammatory genes are associated with periodontitis. Immun Ageing. 2013; 10:39. PMID: 24274085.

[25]. Emampanahi M, Masoudi Rad S, Saghaeian Jazi M, Samaei NM, Behnampour N, Mohammadi S, et al. Association between interleukin-10 gene polymorphisms and severe chronic periodontitis. Oral Dis. 2019; 25:1619-1626.

[26]. Hannum R, Godoy FR, da Cruz AS, Vieira TC, Minasi LB, de Silva D, et al. Lack of association between IL-10 -1082G/A polymorphism and chronic periodontal disease in adults. Genetics and Molecular Research. 2015; 14: 17828-17833.

[27]. Silveira VR, Pigossi SC, Scarel-Caminaga RM, Cirelli JA, Rêgo R, Nogueira NA. Analysis of polymorphisms in Interleukin 10, NOS2A, and ESR2 genes in chronic and aggressive periodontitis. Braz Oral Res. 2016; 30:e105.

[28]. Moudi B, Heidari Z, Mahmoudzadeh-Sagheb H, Moudi M. Analysis of interleukin-10 gene polymorphisms in patients with chronic periodontitis and healthy controls. Dent Res J. 2018; 15:71-9. PMID: 29497450.

[29]. Atanasovska-Stojanovska A, Trajkov D, Popovska M, Spiroski M. IL10 -1082, IL10 -819 and IL10 -592 polymorphisms are associated with chronic periodontitis in a Macedonian population. Human Immunology. 2012; 73: 753-758.

[30]. Berglundh T, Donati M, Hahn-Zoric M, Hanson LA, Padyukov L. Association of the -1087 IL 10 gene polymorphism with severe chronic periodontitis in Swedish Caucasians. J Clin Periodontol. 2003; 30:249-54. https:// scholar.google.com/scholar?hl=en\&as_sdt $=0 \% 2 \mathrm{C} 5 \& \mathrm{q}=$ Association + of + the +\%E2\%80\%911087+IL+10+gene+polymorphism+with+severe+chronic+p eriodontitis+in+Swedish+Caucasians\&btnG=

[31]. Loo W, Fan C, Bai L, Yue Y, Dou Y, Wang M, et al. Gene polymorphism and protein of human pro and anti-inflammatory cytokines in Chinese healthy subjects and chronic periodontitis patients. Journal of Translational Medicine. 2012; 10(Suppl 1): S8. PMID: 23046796.

[32]. Fowler EV, Eri R, Hume G, Johnstone S, Pandeya N, Lincoln D, et al. TNF alpha and IL10 SNPs act together to predict disease behaviour in Crohn's disease. J Med Genet. 2005; 42:523-8. PMID: 15937090.

[33]. Stanilova SA, Miteva LD, Karakolev ZT, Stefanov CS. Interleukin-10-1082 promoter polymorphism in association with cytokine production and sepsis susceptibility. Intensive Care Med. 2006; 32:260-6. PMID: 16435103.

[34]. Cruz M, Fragoso JM, Alvarez-León E, Escobedo-de-la-Peńa J, Adan Valladares, Juárez-Cedillo T, et al. The TGF-B1 and IL-10 gene polymorphisms are associated with risk of developing silent myocardial ischemia in the diabetic patients. Immunol Lett. 2013; 156:18-22. PMID: 24060592. 